\title{
Social learning strategies
}

\author{
KEVIN N. LALAND \\ University of St. Andrews, St. Andrews, Scotland
}

\begin{abstract}
In most studies of social learning in animals, no attempt has been made to examine the nature of the strategy adopted by animals when they copy others. Researchers have expended considerable effort in exploring the psychological processes that underlie social learning and amassed extensive data banks recording purported social learning in the field, but the contexts under which animals copy others remain unexplored. Yet, theoretical models used to investigate the adaptive advantages of social learning lead to the conclusion that social learning cannot be indiscriminate and that individuals should adopt strategies that dictate the circumstances under which they copy others and from whom they learn. In this article, I discuss a number of possible strategies that are predicted by theoretical analyses, including copy when uncertain, copy the majority, and copy if better, and consider the empirical evidence in support of each, drawing from both the animal and human social learning literature. Reliance on social learning strategies may be organized hierarchically, their being employed by animals when unlearned and asocially learned strategies prove ineffective but before animals take recourse in innovation.
\end{abstract}

A common assumption underlying much of the current interest in animal social learning among ethologists and behavioral ecologists is that learning from others is inherently adaptive. Individuals are assumed to benefit by copying because by doing so they take a shortcut to acquiring adaptive information, saving themselves the costs of asocial learning. For instance, by copying others, naive animals could learn the location of valuable food and water sources, how to avoid predators, and how to move safely and efficiently around their environment. Copying, it is assumed, has the advantage that individuals do not need to search their entire home range, sample all potential foods, or evaluate predators for themselves.

Intuitive though this argument may be, it is inherently flawed (Boyd \& Richerson, 1985, 1995; Giraldeau, Valone, \& Templeton, 2002; Rogers, 1988). Copying others per se is not a recipe for success. The reason for this is easy to understand if social learning is regarded as a form of information parasitism (Giraldeau et al., 2002): Social learners are individuals that live at the expense of the population, exploiting the information, skills, and resources acquired, devised, or discovered through asocial learning but contributing no new information themselves. Asocial learners are information producers, whereas social learners are information scroungers. Game theory models of producer-scrounger interactions reveal that

This research was supported by a Royal Society University Research Fellowship to K.N.L. I am grateful to Isabelle Coolen, Rachel Day, LucAlain Giraldeau, Celia Heyes, Jeremy Kendal, Richard McElreath, Karl Schlag, and Yfke van Bergen for discussion and helpful comments on earlier drafts of this manuscript. Correspondence concerning this article should be addressed to K. N. Laland, Centre for Social Learning and Cognitive Evolution, School of Biology, University of St. Andrews, Bute Medical Building, Queen's Terrace, St. Andrews, Fife KY16 9TS, Scotland (e-mail: knl1@ @st-andrews.ac.uk). scroungers do better than producers only when fellow scroungers are rare, whereas at equilibrium the payoffs for producing and scrounging are equal (Barnard \& Sibly, 1981). In identical fashion, theoretical analyses of the evolution of social learning reveal that social learners have higher fitness than asocial learners when copying is rare, because most potential demonstrators are asocial learners who will have sampled accurate information about the environment at some cost (Boyd \& Richerson, 1985, 1995; Giraldeau et al., 2002; Rogers, 1988). ${ }^{1}$ However, as the frequency of social learners increases, the value of copying declines, because the proportion of asocial learners producing reliable information is decreasing. At the extreme, all individuals would be copying fellow copiers with no one sampling the environment, which would make social learning a strategy that has lower fitness than asocial learning. The population is expected to reach an equilibrium at which social and asocial learning will be equal in fitness (Barnard \& Sibly, 1981; Rogers, 1988).

These theoretical analyses reveal that copying others indiscriminately is not adaptive and will not increase the mean fitness of individuals in the population (Boyd \& Richerson, 1985; Giraldeau et al., 2002; Rogers, 1988). Either some individuals in the population must be consistent information producers and rely exclusively on asocial learning or, more realistically, individuals must use social learning selectively and directly sample the environment through their own asocial learning some of the time. It is precisely because individuals do not use social learning indiscriminately and engage in asocial sampling of environments that social learning is typically adaptive (Galef, 1995).

Thus, both game theory and population genetic models lead to the prediction that animals ought to be selective with respect to the circumstances under which they 
rely on social learning and the individuals from whom they learn. A history of natural selection in animals capable of social learning ought to have favored specific adaptive social learning strategies that dictate the contexts under which individuals will exploit information provided by others. The adoption of such strategies would not require that the animals be aware that they are following a strategy, nor that they understand why such strategies may work. Moreover, in accordance with behavioral ecologists' use of the phenotypic gambit (Grafen, 1984), it does not matter whether animals adopt such strategies as a consequence of evolved psychological mechanisms, learning, culture, or some combination of processes. Strategies can still fruitfully be studied as if the simplest genetic system controlled them.

In most studies of social learning in animals, no attempt has been made to investigate the nature of the strategy adopted by animals when they copy others. Researchers have expended considerable effort in exploring the psychological processes that underlie social learning, amassed extensive data banks recording the diffusion of innovations, and mapped geographical variation in the purported cultural traits of countless species, yet the contexts under which animals copy others remain unexplored. Do animals copy the behavior of others when they are uncertain how to solve a problem? Do they copy others when it is easy to do so and learn asocially only when this option is not available? Or, is social learning a last resort when asocial learning has failed? And whom do they copy: the dominant individual? the most successful individual? the majority? Although such questions have received attention from theoreticians, they await explicit experimental analysis. Nonetheless, a large number of incidental findings, discussed below, suggest that animals employ strategies more complex than unselective and indiscriminate copying of others. These findings are largely in accordance with the predictions of theoretical models, but in the absence of direct experimental analyses they can be regarded only as providing circumstantial support for the theory.

A principal goal of this article is to encourage greater experimental and theoretical analysis of the strategies that animals, including humans, adopt when they learn from each other. I use the term strategies in a deliberate attempt to equate such learning heuristics with those strategies subject to analyses by evolutionary game theory. Some of the theoretical findings that I will be describing are based on such theory (Giraldeau \& Caraco, 2000; Schlag, 1998). However, there are clear opportunities to develop this theoretical foundation further by pitting a range of nonlearning, asocial learning, and social learning strategies against one another. For the purpose of clear exposition, in the following treatment I separate social learning strategies into two categories: (1) "when" strategies, which specify the circumstances under which individuals copy others, and (2) "who" strategies, which identify from whom individuals learn. In both cases, I discuss a number of possible heuristics that are predicted by theoretical analyses and consider the empirical evidence in support of each. A summary of the social learning strategies discussed is given in Table 1. Similar, if less extensive, treatments can be found in Laland (2001) and Henrich and McElreath (2003).

\section{"When" Strategies}

The simplest "when" strategy is perhaps to copy when established behavior is unproductive. Here, "established behavior" could refer to unlearned behavior or to the learned solutions to related problems. For example, Lefebvre and Palameta (1988) conducted an investigation of the spread of a food-finding behavior in populations of pigeons, in which the birds were required to peck open a carton containing seed. The pigeons would scrounge (take food from others) if possible, and only when there were so few birds producing food that scrounging was unproductive did some scroungers switch to adopting the food-finding behavior. The suggestion that this reflects a strategy of learning only when there is no easier option is supported by the facts that scroungers and producers switch strategy to maintain a frequency-dependent balance and that the proportion of scroungers diminishes as the producers share increases (Giraldeau \& Beauchamp, 1999). That is, when there aren't enough producers to go around, the returns to scroungers are poor, and some scroungers will learn to produce. When there are too many producers, however, the returns to scroungers will be much greater, and some producers will revert back to scrounging. Note that here the use of the copy-whenestablished-behavior-is-unproductive strategy refers to the initial acquisition of the producing behavior; whether or not individuals continue to produce or switch back to scrounging depends on the respective payoffs. The fact that earlier experimental analyses had established that asocial learning of the task was unlikely suggests that, in this instance, social learning underpinned adoption of the producer strategy (Lefebvre \& Palameta, 1988). Implicit in this account are the assumptions that social learning can facilitate the adoption of a producer strategy but that no learning is required to scrounge.

Table 1 Social Learning Strategies

\section{"When" Strategies}

Copy when established behavior is unproductive Copy when asocial learning is costly

Copy when uncertain

"Who" Strategies

Copy the majority

Copy if rare

Copy successful individuals

Copy if better

Copy if dissatisfied

Copy good social learners

Copy kin

Copy "friends"

Copy older individuals

Note- "When" strategies specify the circumstances under which individuals copy others, and "who" strategies identify from whom individuals learn. Here, the term copy refers to any form of social learning. 
Theoretical models typically assume that any individual in a population of social foragers should use scrounging when the opportunity arises, as long as the opportunity is detected and scrounging is not associated with significant costs (Giraldeau \& Caraco, 2000). The hypothesis that scrounging is a first or preferred strategy and learning to produce is a resort used only when scrounging is unprofitable or costly is supported by evidence that the opportunity to scrounge blocks the learning of a producer tactic. Giraldeau and Lefebvre (1987) reached such a conclusion after finding that pigeons that obtained food as a result of a demonstrator's removal of a stopper to a container of seed were poor at learning the stopper-removal behavior in comparison with birds that received no food during demonstration. Similar observations have been reported in zebra finches (Beauchamp \& Kacelnik, 1991) and tufted capuchins (Fragaszy \& Visalberghi, 1990). Giraldeau and Lefebvre (1986) observed that scrounger pigeons that switched to producing when producers had been removed from the population switched back to scrounging when the producers were returned. This is consistent with the conclusion that scrounging is a preferred strategy, but also with the suggestion that individuals adopt whatever strategy has the highest payoff at the time. Perhaps the most compelling evidence that, all other factors being equal, individuals would prefer to scrounge than to learn to produce is provided by the limited evidence that dominant individuals (who presumably have the choice) are more likely to be scroungers than subordinate individuals (Barta \& Giraldeau, 1998; Giraldeau \& Caraco, 2000).

The observation that scrounging blocks learning of a means of production is consistent with the producerscrounger models' assumption that a forager cannot simultaneously play producer and scrounger tactics (Barnard \& Sibly, 1981). This assumption distinguishes most producer-scrounger models from information-sharing models (Giraldeau \& Caraco, 2000), with the latter allowing individuals to search for food and look for scrounging opportunities at the same time. The fact that producer and scrounger tactics are not always strictly incompatible is supported by the observation that individuals can seemingly learn to produce while scrounging or as a result of scrounging. For instance, Giraldeau and Lefebvre (1987) also found that pigeons that had previously scrounged were subsequently more likely to exhibit the resource-producing behavior than pigeons in a control group that had not observed production. Similarly, Fritz and Kotrschal (1999) concluded that scrounging in common ravens did not inhibit learning, since individuals that scrounged from demonstrators were more likely to learn the resource-producing behavior than were those in the absence of a demonstration. Thus, scrounging appears to facilitate learning (or, perhaps, not to eradicate all the facilitatory effects of observing production) for naive individuals, but to impede learning for observers with no opportunity to scrounge.

Giraldeau, Caraco, and Valone (1994), motivated by observations of social foraging in pigeons, developed a mathematical model to explore how the costs and benefits of social learning are effected by scrounging. They concentrated on within-generation social learning of a trait that enhances resource production, assuming both frequency-dependent asocial learning (which decreases due to scrounging, since an animal that scrounges reduces its opportunity for learning through its own experiences) and frequency-dependent social learning (which increases with the number of demonstrators). The acquired trait results in an increased ability to find resource clumps relative to a baseline rate. Giraldeau et al. (1994) found that social learning increased the expected number of individuals foraging at the elevated rate relative to asocial learning, and with no social learning there was a significant fitness cost to group foraging. They hypothesized that the adaptive function of social learning may be to allow individuals to circumvent some of the inhibitory effects that scrounging has on asocial learning of a foraging skill, and thereby to learn to produce.

Theoretical analyses used in the exploration of the adaptive advantages of social learning have led to a consensus that greater reliance on social learning should be favored as the costs of asocial learning increase (Boyd \& Richerson, 1985, 1988; Feldman, Aoki, \& Kumm, 1996). Such costs include the energetic costs of searching for and processing valuable resources, the risk of unreliable (asocially acquired) information, as well as the viability deficits associated with hazardous asocial learning, such as the learning of antipredator behavior through direct experience. Such theory implies that a copy-whenasocial-learning-is-costly strategy might be adaptive, a suggestion consistent with Boyd and Richerson's (1985) costly information hypothesis. ${ }^{2}$ This hypothesis focuses on the evolutionary tradeoff between acquiring accurate but costly information versus less accurate but relatively cheap information. Boyd and Richerson (1985) suggest that when information is too costly to acquire or utilize personally, individuals will take advantage of the relatively cheap information provided by others. For example, Templeton and Giraldeau (1996) found that European starlings used public information concerning the foraging successes and failures of conspecifics only when accurate information about patch quality was difficult or costly to acquire via personal sampling alone. It is easy to envisage circumstances under which information might be costly to acquire asocially (e.g., learning the identity of predators or predator evasion tactics). It is, perhaps, no coincidence that there is considerable evidence for the social learning of antipredator behavior in animals (Chivers \& Smith, 1995; Kelley, Evans, Ramnarine, \& Magurran, 2003; Krause, 1993; Mineka \& Cook, 1988; Suboski \& Templeton, 1989).

Solving challenging problems asocially frequently requires a considerable investment of energy. Hence, another common circumstance in which established solutions are likely to prove unproductive is that in which individuals are confronted with particularly difficult novel tasks. If solutions to related tasks have failed to de- 
liver a reward, individuals would have little to lose from seeking guidance from others. ${ }^{3}$

The assumption that some tasks are so difficult that they are unlikely to be learned asocially can frequently be observed in the social learning literature. For instance, Byrne (1999; Byrne \& Russon, 1998) has argued that the elaborate, hierarchically organized food-processing techniques exhibited by gorillas in consuming plants with physical and chemical defenses are likely to be acquired through program-level imitation, since they are too complex for an individual to acquire asocially. Byrne and Russon (1998) write: "Learning by individual experience is not completely disproven by these data, but it becomes a contrived alternative" (p. 676). The reasoning here is that the time and energy that would have to be invested to devise such food-processing methods, and the pain and discomfort associated with experiencing and learning to circumvent the plants' chemical and physical defenses, result in substantial costs to asocial learning.

Few empirical studies have directly explored whether and how the probability of social learning is influenced by task difficulty. An exception are those of Day (2003; Day, Coe, Kendal, \& Laland, 2003), who presented a series of novel puzzle box tasks to captive populations of callitrichid monkeys. Judging by the mean time required for the monkeys to solve them, the tasks varied significantly in difficulty, although at this stage it is not clear precisely what it was that made some tasks more difficult than others. Each puzzle box could be opened in one of two ways (e.g., by opening one of two doors) to access food, with the alternatives differing in location and color but being otherwise equivalent. Although the monkeys learned all the tasks, a detailed statistical analysis revealed evidence that the means of opening the difficult puzzle boxes, but not the easier ones, were learned socially. Presumably, easy puzzle box tasks could be solved through asocial learning at little personal cost (in terms of time and energy) to the solver, whereas the solutions of more complex puzzles were associated with a sufficiently large cost to render social learning adaptive. Similar observations have been reported in human subjects, who were found to imitate more as task difficulty increased (Baron, Vandello, \& Brunsman, 1996).

Boyd and Richerson $(1985,1996)$ have argued that so much of contemporary human existence is reliant on sophisticated technology, which the vast majority of individuals could not invent for themselves, that we essentially have no choice but to copy others. If pushed, we might be able to improvise a new recipe or manufacture some crude clothing for ourselves, but how many among us could build a computer or devise a treatment for diabetes? Henrich and McElreath (2003) illustrate this point beautifully with the story of three European explorers who, in spite of having specialized equipment and training, failed to work out for themselves how to survive in the Australian desert, where aboriginal groups comfortably forge a living on the land. Adaptive behavior in humans is heavily reliant on socially transmitted knowl- edge that accumulates over generations, such as the knowledge that the aborigines possessed but the explorers lacked. For most of us, our almost complete reliance on the accumulated knowledge of previous generations in order to survive renders the cost of inventing equivalent solutions through asocial learning unrealistically high. At the same time, by creating environments with transgenerational stability, through our niche construction we humans modify our worlds in such a way as to facilitate effective learned information transmission between individuals and across generations (Laland, Odling-Smee, \& Feldman, 2000; Odling-Smee, Laland, \& Feldman, 2003), rendering the costs of social learning remarkably low. With the balance sheet weighted so heavily, it is little wonder that our species is so reliant on culture.

In circumstances in which asocial learning is associated with significant costs or social learning is associated with substantive benefits, doing what others do may be adaptive for an individual even if the population's behavior is suboptimal. In game theoretical terms, arbitrary and even maladaptive traditions may emerge as Nash equilib$\mathrm{ria}^{4}$ if each individual is reinforced for doing what others are doing or penalized for breaking the convention (Boyd \& Richerson, 1985, 1992; Giraldeau et al., 2002). For instance, Laland and Williams (1998) found that guppies will swim an energetically costly long route to feed when a short route is available, provided that conspecifics take the long but not the short route. Solitary fish learn to take the short route very quickly, but fish in a laboratory tradition taking the long route take a much longer time to adjust to the shorter route. If one regards the ecological environment as the sole source of reward, it is difficult to explain why fish exposed to the tradition should take longer than solitary fish to adopt the short route. But if one recognizes the rewards of the social environment (in this case, the benefits of aggregation for effective predator defense) and the costs of asocial learning (an elevated risk of predation), then it becomes possible to envisage animal traditions that are inherently self-perpetuating. ${ }^{5}$ Pongrácz, Miklósi, Kubinyi, Topál, and Csányi (2003) also report that social learning can perpetuate maladaptive foraging traditions among dogs, whereas Giraldeau et al. (2002) discuss a number of possible cases in which maladaptive behavior may spread as a result of informational cascades in which individuals base behavioral decisions on the prior decisions of others.

There are other plausible "when" strategies. For instance, Boyd and Richerson (1988) considered a theoretical model exploring the adaptive advantages of social learning in a variable environment (see also Henrich $\&$ Boyd, 1998). The model assumed that individuals were required to make a judgment as to which of two environments they were in and to produce the behavior that was appropriate to that environment. Boyd and Richerson (1988) postulated that animals would rely on their own experience when reasonably certain which environment they were in, but would rely on social learning when the nature of the environment was unclear. This 
suggests that a copy-when-uncertain strategy may sometimes be employed by animals.

I know of no experimental data that directly confirm Boyd and Richerson's (1988) assumption that animals copy because they are uncertain as to which preestablished behavior pattern is appropriate, although there is data suggesting that animals copy when uncertain because they possess no relevant prior knowledge. ${ }^{6}$ For example, Galef and colleagues have established that rats, when confronted with two alternative novel foods, preferentially adopt the diet consumed by conspecifics as indicated by odor cues on their breath (see Galef, 1996, for a review). Interestingly, when the foods were familiar, the demonstrators' influence was much weaker, suggesting that social information is of greatest utility when the rat is uncertain as to which diet to consume. Similarly, Day, Coolen, and Laland (in press) observed that guppies with no prior knowledge of the whereabouts of food, finding themselves in a novel environment, will adopt the foraging behavior of conspecifics, whereas those with prior knowledge will ignore the foraging information provided by conspecifics. Day et al. (in press) also found that if the use of private (asocially acquired) information was made actually or potentially costly, in this case by requiring fish to swim away from and break visual contact with the shoal, then fish ignore their prior knowledge and utilize the social information provided by foraging conspecifics. The latter finding, which suggests a copy-when-asocial-learning-is-costly strategy, is consistent with Boyd and Richerson's (1988) costly information hypothesis.

\section{"Who" Strategies}

In a landmark paper exploring the relation between social dynamics and social learning, Coussi-Korbel and Fragaszy (1995) stressed the concept of directed social learning, according to which the identity and characteristics of demonstrator and observer critically affect the probability of social learning. Coussi-Korbel and Fragaszy suggested that the social rank, sex, age, patterns of association, and other characteristics of demonstrator and observer frequently influence the likelihood of social learning. As a result, information may be transmitted through subsections of animal societies at different rates. Coussi-Korbel and Fragaszy's argument was based primarily on observations of nonhuman primates, but their conjectures are supported by mathematical analyses exploring the evolution of social learning. Such analyses have concluded that humans and animals alike should be selective with respect to the individuals from whom they learn, and a considerable amount of modeling effort has gone into exploring the relative merits of alternative strategies specifying whom to copy in order to maximize the effectiveness of social learning.

Theoretical analyses have revealed that in most circumstances in which natural selection favors reliance on social learning, conformity is also favored (Boyd \& Richerson, 1985). Here, conformity refers to positive, frequency-dependent social learning in which the probability of acquiring a trait increases disproportionately with the number of demonstrators performing it. Henrich and Boyd (1998) recently established that a broader range of conditions favors conformist transmission as opposed to cultural transmission. These findings suggest that much animal social learning should involve individual adoption of the behavior of the majority - that is, a copy-the-majority strategy. Although few empirical studies on animals have addressed this issue directly, social learning in which the probability of adopting a pattern of behavior increases with the proportion of demonstrators occurs in guppies (Lachlan, Crooks, \& Laland, 1998; Laland \& Williams, 1997; Sugita, 1980), rats (Beck \& Galef, 1989; Chou \& Richerson, 1992), pigeons (Lefebvre \& Giraldeau, 1994), and humans (see Boyd \& Richerson, 1985, and Henrich, 2001, for reviews). Strictly speaking, this work provides only weak evidence of conformity, since the experiments would need to demonstrate a disproportionate tendency to adopt the behavior of the majority rather than a linear association between the probability of learning and the proportion of demonstrators exhibiting the behavior. There is also evidence that some birds acquire their songs from neighbors in a conformist manner (Catchpole \& Slater, 1995; Payne, 1996). The results of shoal choice experiments in fish, in which individuals were given a choice between joining two shoals that differed in the number of composite individuals, are also consistent with the conjecture that conformity is operating (Krause \& Godin, 1994; Lachlan et al., 1998; Lindström \& Ranta, 1993).

Animals may adopt a conformist strategy in their mate choice decisions, choosing partners according to their popularity. Mate choice copying is said to have occurred when the probability of an individual's selecting another as a sexual partner increases because other individuals (of the same sex) have selected the same partner (Gibson \& Höglund, 1992). A series of experiments by White and Galef $(1999,2000$; Galef \& White, 1998) provide evidence that female quail copy one another's mate choices. Experiments with guppies suggest that females may utilize the presence of a female near a courting male as an indication of his quality and bias their choices of males accordingly (Dugatkin, 1992). However, there are a number of other interpretations, and researchers have struggled to replicate some prominent findings (Brooks, 1996; LaFleur, Lozano, \& Sclafani, 1997).

Day, MacDonald, Brown, Laland, and Reader (2001) found stronger evidence of conformity in a series of experiments in fish in which the effect of shoal size on foraging efficiency was investigated. In a first experiment, they presented a hidden food source to shoals of guppies in open water. Large shoals were found to locate food faster than small shoals, in consistency with similar findings in other fishes. This is probably because fish in large shoals have more shoal mates from which to acquire information, and large numbers of individuals at a food site attract conspecifics more rapidly than small ag- 
gregations. However, in a second experiment, the fish had to swim through a hole in an opaque maze partition to get to a food source. In this situation, the opposite result was found: Smaller shoals located food faster than larger shoals. The seemingly conflicting findings of these experiments make sense in light of the observation that guppies have a preference to join large over small shoals, which implies that individuals ought to be more willing to leave smaller than larger shoals. Swimming through an opaque partition to locate food involved breaking visual contact with the shoal and, hence, effectively leaving it. Under such circumstances, conformity, which is the result of the natural shoaling tendency of these fish, leads to greater reluctance to acquire a novel behavior in large than in small shoals. This interpretation was supported by the findings of a third experiment, which replicated the second except that it made use of a transparent partition. In this experiment, individuals in large shoals once again located the food faster than those in small shoals. Here, visual contact between fish was maintained because the partition was transparent, so fish passing through it were not leaving the shoal. Hence, social transmission of foraging information was not hindered by conformity, and large shoals were advantaged.

Conformity is a manifestation of positive, frequencydependent social learning. In theory, the reverse pattern of negative frequency dependence might occur under restricted circumstances in which novelty confers a selective advantage. In the same way that rare males have a mating advantage in populations of Drosophila, so rare behavior patterns may be disproportionately adopted with the use of a copy-if-rare strategy. One example that may fit the bill is interspecific vocal mimicry in birds such as starlings, parrots, and mynahs. At the extreme, male European marsh warblers copy the sounds of an average of 77 other species (Dowsett-Lemaire, 1979). Catchpole and Slater (1995) suggest that in species in which males habitually copy the vocalizations of heterospecifics, the most likely explanation is that this is a result of sexual selection, females favoring males with large repertoires. They point out that the most striking cases of vocal mimicry occur in species with very elaborate songs.

Obviously, learning from others will be more effective if animals disproportionately adopt the behavior of the more successful members of the population. There is no point in copying someone whose behavior is manifestly unproductive. There are a number of related strategies that could be adopted here, the utility of which has been explored using theoretical models. One such strategy is to copy successful individuals, the latter being identified by cues such as health, wealth, or reproductive success. Boyd and Richerson (1985) labeled this kind of strategy an "indirect bias." Theoretical analyses suggest that this can be an effective strategy and typically leads to adaptive behavior (Boyd \& Richerson, 1985; Kendal, 2003).

A copy-successful-individuals strategy has the advantage of being relatively easy to implement, but the dis- advantage that it is not always clear which of a successful individual's many traits is the major source of its success. Pop and film stars do not make their millions as a result of their political views, yet they frequently exert an influence on the political beliefs and values of their fans. Mathematical analyses suggest that this strategy may be favored by natural selection even though it may sometimes allow neutral and maladaptive traits to hitchhike along with those traits that engender success (Boyd \& Richerson, 1985). Some animals also appear to adopt this strategy, although there are other possible interpretations. ${ }^{7}$ For instance, the probability that redwing blackbirds will acquire a food preference through social learning is affected by whether the demonstrator bird becomes sick or remains well (Mason, 1988). Bats that are unsuccessful in locating food alone follow previously successful bats to feeding sites (Wilkinson, 1992). In studies of foraging behavior in chimpanzees, Menzel (1973, 1974) found that naive chimpanzees were more likely to follow an informed individual with knowledge of the whereabouts of hidden food than an uninformed conspecific. A similar phenomenon has been reported in guppies (Lachlan et al., 1998).

Henrich and Gil-White (2001) suggest that the evolution of a copy-successful-individuals strategy could explain the formation of prestige hierarchies, since highly skilled individuals will be at a premium. Individuals adopting this strategy may be selected to pay deference to successful individuals in exchange for preferred access and assistance in learning. Henrich and Gil-White suggest that such deference benefits may take many forms, some of which may apply to animals, including coalition support, gifts, and caring for offspring. Eventually, such deference behavior itself becomes a reliable cue as to which individuals possess adaptive knowledge.

In the context of animal studies, prestige may equate to social rank. Are animals more likely to copy highranking than low-ranking conspecifics? Surprisingly few attempts have been made to address this question. However, evidence is beginning to emerge from studies of birds and monkeys that low-status demonstrators may be ineffective relative to high-status demonstrators because of the inhibiting effects of the presence of conspecifics on the performance of their behavior (Drea \& Wallen, 1999; Nicol \& Pope, 1994).

A closely related alternative strategy is to copy the most successful behavior, which requires individuals to evaluate the payoffs associated with behavioral alternatives. This ability is a standard assumption of theoretical models of human decision making (Gintis, 2000; Schlag, 1998), but it is not clear to what extent animals are able to make such judgments. The collection of information about relative patch quality by monitoring the success of others has been called public information use (Valone, 1989). Public information use has been reported in the selection of food patches and breeding sites in birds (Doligez, Danchin, \& Clobert, 2002; Templeton \& Giraldeau, 1996) and in assessment of the relative value of mates and competi- 
tors by fish (McGregor, Peake, \& Lampe, 2001). For instance, starlings can use the foraging success of other birds to assess patch quality, and they exploit this information in their judgments as to whether to stay or switch patches (Templeton \& Giraldeau, 1996).

Another heuristic is copy if better, whereby individuals switch strategy if the returns of the behavior adopted by the demonstrator exceed those of their own behavior (Schlag, 1998). Schlag's game theoretical analyses reveal that when information concerning the success of others is unreliable and noisy, a copy-if-better strategy outperforms a copy-the-most-successful-behavior strategy. However, Schlag reports that in risky environments always copying all individuals that seem to be reaping greater returns can lead the entire population to choose the alternative with the lowest expected payoff. A much better rule, which Schlag calls "proportional imitation," is one by which observers copy an individual that performed better than they did with a probability that is proportional to how much better that individual performed. Schlag found that this version of the copy-if-better strategy always leads the population to the expected payoffmaximizing action.

Recent human culture is characterized by the ratchet effect (Tomasello, 1994), or an increase in the complexity or efficiency of technology over time. There is little direct evidence within animal populations of additive, incremental improvement in behavior or technological advance (although see Hunt \& Gray, 2003), which has led to the argument that certain key psychological abilities are critical to cumulative evolution. Capacities for teaching and imitation have been widely touted as likely candidate processes (Boyd \& Richerson, 1985; Galef, 1992; Tomasello, 1994), but Schlag's (1998) findings suggest another possibility. Intrinsic to ratcheting is the ability to make a judgment that a novel solution to a problem generates superior returns than does an established behavior. Perhaps other species rarely exhibit ratcheting because individuals are unable to ascertain with sufficient reliability whether the behavior of another individual is more profitable than their own, or are unable to make a judgment as to how much better the alternative is. Conceivably, the ability to implement Schlag's proportional imitation rule requires an accuracy of appraisal that is typically absent in nonhuman primates, making a copy-if-better strategy less likely to be adaptive.

Schlag's (1998) analysis has uncovered two further strategies that appear to be equally as effective as "proportional imitation" but may be easier for animals to use. One such strategy, which he terms "proportional observation," requires individuals to copy the behavior of a demonstrator with a probability equal to the demonstrator's payoff. Thus, once again, animals have to make a judgment as to the profitability of another individual's behavior, but this rule seems less complicated than the proportional imitation rule, since a comparison between self and other is not required. However, even Schlag
(May, 2003, personal communication) expresses reservations about whether a strategy independent of one's own success could evolve. Surely animals would take into account the returns of their current behavior before copying others. Perhaps more realistic is a rule that Schlag termed "proportional reservation," but which might be called the copy-if-dissatisfied strategy. Here, the size of the payoff to an individual's current behavior determines its satisfaction, in a linear function. The individual retains its current behavior with a probability equal to this satisfaction. Hence, if the level of satisfaction is low there is a large probability that it will copy the action of a randomly chosen demonstrator, whereas if its satisfaction is high the probability is small. This strategy has the advantage that it is potentially simple to implement, because it does not require individuals to assess the payoff to a demonstrator or to make any judgments as to the relative profitability of alternative behavior patterns. The copyif-dissatisfied strategy is interesting, not least because animals could feasibly use it. Schlag's analysis suggests that the proportional-imitation, proportional-observation, and proportional-reservation tactics will all have equal fitness at equilibrium. However, the proportional-reservation rule would appear to be easier to implement than the other two strategies. Thus, we might anticipate that a copy-ifdissatisfied strategy is likely to be widespread in nature, whereas a copy-if-better strategy will probably be rarean easily testable prediction.

The evolution of enhanced brain size in primates has commonly been explained in terms of selection favoring social or technical intelligence. As an alternative hypothesis, Blackmore (1999) has suggested that the selection pressure to acquire fitness-enhancing memes (i.e., cultural units analogous to genes) drove the evolution of effective imitators by favoring an imitate-thebest-imitators strategy, with effective social learning requiring large brains. Blackmore's argument was based on the assumption that the most effective social learners would acquire the most advantageous cultural traits. Hence, her copy-the-good-social-learners strategy is intrinsically tied to a copy-the-most-successful-behavior strategy. Theoretical support for Blackmore's argument is mixed. An analysis by Higgs (2000) concluded that Blackmore's hypothesis is plausible, although the extent to which his model actually tests Blackmore's hypothesis has been challenged (Barrett, Dunbar, \& Lycett, 2002; Kendal, 2003). Conversely, Kendal (2003) found that a copy-the-good-social-learners strategy would not evolve, since it has no selective advantage over the strategy used by generalist social learners that copy other individuals at random. On the other hand, Kendal did find that a copy-the-most-successful-behaviorstrategy would evolve. One empirical observation consistent with Blackmore's hypothesis is Nowicki, Searcy, and Peters's (2002) report that female song sparrows prefer the songs of males that copy accurately. Nowicki et al. suggest that song-learning ability is a reliable indicator of male quality. 
An extremely common observation in the social learning literature is that individuals often copy kin. Any kin bias may reflect nothing more than the fact that individuals spend considerably more time in the presence of kin than in that of nonkin. However, there are two reasons to suspect that selection may have favored a disproportionate degree of learning from kin. First, social learning, particularly in a variable environment, is of use only to the extent that demonstrator and observer experience the same environment and reap the same rewards (Boyd \& Richerson, 1985, 1988). This may be more likely among kin than among nonkin because, by virtue of their shared genes (and other sources of similarity), kin may be more likely than nonkin to reproduce similar behavior variants and to experience the same affective sensations in reinforcement. ${ }^{8}$ Second, in situations in which information transmission is costly, because of their shared genes individuals may have more to gain by providing reliable information to kin than to nonkin, and less to gain from deceiving them. Conceivably, Hamilton's (1964) rule may apply to social learning, with the probability of social learning being directly proportional to the coefficient of relatedness of observer and demonstrator. It may be no coincidence that one of the most sophisticated cases of animal communication that results in social learning - the famous dance of the honeybee-occurs among female worker bees that share up to three quarters of their genes. Similarly, if "friends" are regarded as individuals with whom one trades altruistic acts (Trivers, 1971), by similar lines of reasoning we might expect more social learning among friends than among nonfriends in a copy-friends strategy. Although fish may not have "friends," they do express preferences for shoaling with familiar individuals (Griffiths, 2003), and guppies have been reported to acquire foraging information more effectively from familiar than from unfamiliar demonstrators (Swaney, Kendal, Capon, Brown, \& Laland, 2001). Another possible strategy, copy older individuals, has been assumed in theoretical analyses (Kirkpatrick \& Dugatkin, 1994) on the basis of reports of mate choice copying in female guppies.

\section{Hierarchical Control of Social Learning Strategies}

The preceding discussion hints at a hierarchical control in the deployment of social learning. "When" strategies imply that individuals resort to social learning only when unlearned or asocially learned solutions are ineffective. Although not discussed here, much research into animal innovation is consistent with a "necessity is the mother of invention" interpretation (Reader \& Laland, 2003). Innovation is a process that results in new or modified learned behavior and that introduces novel behavior into a population's repertoire (Reader \& Laland, 2003). If innovation is risky and associated with costs, then it is likely to be employed as a last resort when unlearned or asocially learned, or when socially learned strategies have proven unproductive. There are good evolutionary reasons for anticipating hierarchical organization of behavior (Dawkins, 1976), and hierarchical control has been reported for a great deal of human and animal behavior (Byrne \& Russon, 1998). In Figure 1, this reasoning is structured in the form of a flow chart.

The hierarchical scheme depicted in Figure 1 is simplistic and speculative and is likely to be wrong in important respects: There may not be consistent patterns in animals' reliance on unlearned and learned behavior; perhaps strategies will be found to be organized hierarchically, but in a different manner from that portrayed here; conceivably, there will be feedback between levels;

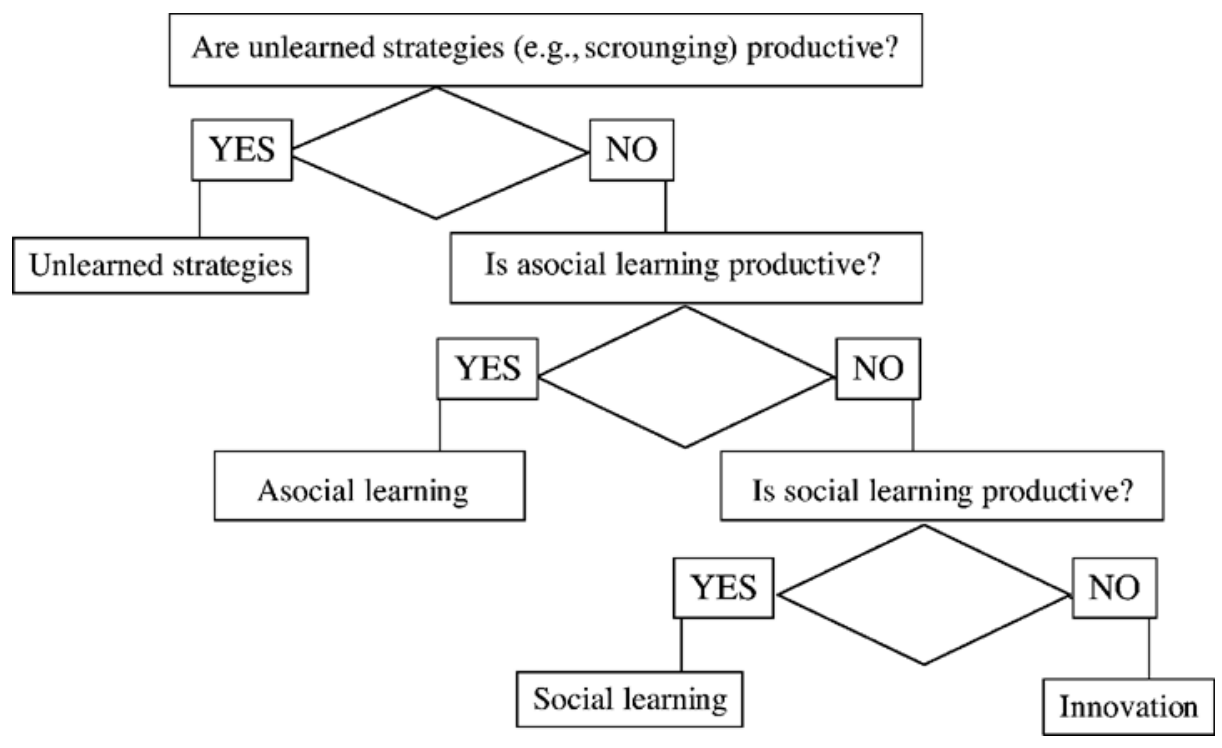

Figure 1. Hierarchical control of behavioral strategies. 
and so on. Nonetheless, I persist with this scheme in the hope that it will encourage other researchers to formulate more sophisticated analyses of the control of learning strategies.

Irrespective of how useful a hierarchical conception of the deployment of social learning strategies proves, greater attention to the contexts in which human and nonhuman animals utilize social learning is surely warranted. There is a need for empirical research explicitly evaluating the strategies proposed by theoretical models. At the same time, further theoretical analyses of the relative merits of different strategies in different contexts would be of considerable value, most likely using evolutionary game theoretical models. What makes social learning strategies an exciting avenue for future research are the rich possibilities for integrating empirical and theoretical findings. The approach has the additional advantage that, potentially, it helps to draw the field of social learning more closely into a general behavioral ecology framework.

\section{REFERENCES}

BARNARD, C. J., \& SiBly, R. M. (1981). Producers and scroungers: A general model and its application to captive flocks of house sparrows. Animal Behaviour, 29, 543-550.

Baron, R. S., VAndello, J. A., \& Brunsman, B. (1996). The forgotten variable in conformity research: The impact of task importance on social influence. Journal of Personality \& Social Psychology, 71, 915-927.

BARrett, L., Dunbar, R., \& LyCetT, J. (2002). Human evolutionary psychology. London: Macmillan.

BARTA, Z., \& GiRAldEAU, L.-A. (1998). The effect of dominance hierarchy on the use of alternative foraging tactics: A phenotype-limited producing-scrounging game. Behavioral Ecology \& Sociobiology, 42, 217-223.

BEAUCHAMP, G., \& KACELNIK, A. (1991). Effects of the knowledge of partners on learning rates in zebra finches Taeniopygia guttata. Animal Behaviour, 41, 247-254.

BECK, M., \& GALEF, B. G., JR. (1989). Social influences on the selection of a protein-sufficient diet by Norway rats Rattus norvegicus. Journal of Comparative Psychology, 103, 132-139.

BlaCKMORE, S. (1999). The meme machine. Oxford: Oxford University Press.

Boyd, R., \& RichERSON, P. J. (1985). Culture and the evolutionary process. Chicago: University of Chicago Press.

BOYD, R., \& RichERSON, P. J. (1988). An evolutionary model of social learning: The effects of spatial and temporal variation. In T. Zentall \& B. G. Galef (Eds.), Social learning: A psychological and biological approach (pp. 29-48). Hillsdale, NJ: Erlbaum.

Boyd, R., \& RichERSON, P. J. (1992). Punishment allows the evolution of cooperation (or anything else) in sizable groups. Ethology \& Sociobiology, 13, 171-195.

BOYD, R., \& RiCHERSON, P. J. (1995). Why does culture increase human adaptability? Ethology \& Sociobiology, 16, 125-143.

BOYD, R., \& Richerson, P. J. (1996). Why culture is common, but cultural evolution is rare. Proceedings of the British Academy, 88, 73-93.

Brooks, R. (1996). Copying and the repeatability of mate choice. Behavioral Ecology \& Sociobiology, 39, 323-329.

BYRNE, R. W. (1999). Cognition in great ape ecology: Skill-learning ability opens up foraging opportunities. In H. O. Box \& K. R. Gibson (Eds.), Mammalian social learning: Comparative and ecological perspectives (pp. 333-350). Cambridge: Cambridge University Press

BYRNE, R. W., \& Russon, A. E. (1998). Learning by imitation: A hierarchical approach. Behavioral \& Brain Sciences, 21, 667-684.

CAtchpole, C. K., \& Slater, P. J. B. (1995). Bird song: Biological themes and variations. Cambridge: Cambridge University Press.
Chivers, D. P., \& Smith, J. F. (1995). Chemical recognition of risky habitats is culturally transmitted among fathead minnows, Pimephales promelas (Osteichthyes, Cyprinidae). Ethology, 99, 286-296.

CHOU, L. S., \& Richerson, P. J. (1992). Multiple models in social transmission of food selection by Norway rats, Rattus norvegicus. Animal Behaviour, 44, 337-343.

Coussi-Korbel, S., \& Fragaszy, D. M. (1995). On the relation between social dynamics and social learning. Animal Behaviour, 50, 1441-1453.

DAWKINS, R. (1976). Hierarchical organisation: A candidate principle for ethology. In P. P. G. Bateson \& R. A. Hinde (Eds.), Growing points in ethology (pp. 7-54). Cambridge: Cambridge University Press.

DAY, R. [L.] (2003). Innovation and social learning in monkeys and fish: Empirical findings and their application to reintroduction techniques. Unpublished doctoral thesis, University of Cambridge.

DAY, R. L., CoE, R. L., Kendal, J. R., \& LALAnd, K. N. (2003). Neophilia, innovation and social learning: A study of intergeneric differences in Callitrichid monkeys. Animal Behaviour, 65, 559-571.

Day, R. L., Coolen, I., \& LAland, K. N. (in press). The role of conformity in guppy foraging when prior personal and social information conflict. Behavioral Ecology.

Day, R. [L.], MacDonald, T., Brown, C., Laland, K., \& Reader, S. M. (2001). Interactions between shoal size and conformity in guppy social foraging. Animal Behaviour, 62, 917-925.

Dolige Z, B., DANChin, E., \& Clobert, J. (2002). Public information and breeding habitat selection in a wild bird population. Science, 297, 1168-1170.

DowsetT-Lemaire, F. (1979). The imitative range of the song of the marsh warbler Acrocephalus palustris, with special reference to imitations of African birds. Ibis, 121, 453-468.

DREA, C. M., \& WALLEN, K. (1999). Low status monkeys "play dumb" when learning in mixed social groups. Proceedings of the National Academy of Sciences, 96, 12965-12969.

DUGATKIN, L. A. (1992). Sexual selection and imitation: Females copy the mate choice of others. American Naturalist, 139, 1384-1389.

Feldman, M. W., AOKI, K., \& KumM, J. (1996). Individual versus social learning: Evolutionary analysis in a fluctuating environment. Anthropological Science, 104, 209-232.

Fragaszy, D. M., \& VisAlberghi, E. (1990). Social processes affecting the appearance of innovative behaviours in capuchin monkeys. Folia Primatologica, 54, 155-165.

FritZ, J., \& KOTRSCHAL, K. (1999). Social learning in common ravens, Corvus corax. Animal Behaviour, 57, 785-793.

GAlef, B. G., JR. (1992). The question of animal culture. Human Nature, 3, 157-178.

GALEF, B. G., JR. (1995). Why behaviour patterns that animals learn socially are locally adaptive. Animal Behaviour, 49, 1325-1334.

GALEF, B. G., JR. (1996). Social enhancement of food preferences in Norway rats: A brief review. In C. M. Heyes \& B. G. Galef, Jr. (Eds.), Social learning and imitation: The roots of culture (pp. 49-64). San Diego: Academic Press.

Galef, B. G., JR., \& White, D. J. (1998). Mate-choice copying in Japanese quail, Coturnix coturnix japonica. Animal Behaviour, 55, 545-552.

Gibson, R. M., \& HöGLund, J. (1992). Copying and sexual selection. Trends in Ecology \& Evolution, 7, 229-232.

GinTIS, H. (2000). Game theory evolving. Princeton, NJ: Princeton University Press.

GIRALDEAU,L.-A., \& BEAUCHAMP, G. (1999). Food exploitation: Searching for the optimal joining policy. Trends in Ecology \& Evolution, 14, 102-106

GiraldeAU, L.-A., \& CARACo, T. (2000). Social foraging theory. Princeton, NJ: Princeton University Press.

Giraldeau, L.-A., Caraco, T., \& Valone, T. J. (1994). Social foraging: Individual learning and cultural transmission of innovations. Behavioral Ecology, 5, 35-43.

GiRAlDEAU, L.-A., \& LEFEBVRE,L. (1986). Exchangeable producer and scrounger roles in a captive flock of feral pigeons: A case for the skill pool effect. Animal Behaviour, 34, 797-803.

GiRAldeAU, L.-A., \& LefebVRe, L. (1987). Scrounging prevents cultural transmission of food finding behaviour in pigeons. Animal Behaviour, 35, 387-394.

Giraldeau,L.-A., Valone, T. J., \& Templeton, J. J. (2002). Potential 
disadvantages of using socially acquired information. Philosophical Transactions of the Royal Society of London, 357, 1559-1566.

GRAFEN, A. (1984). Natural selection, kin selection and group selection. In J. R. Krebs \& N. B. Davies (Eds.), Behavioural ecology: An evolutionary approach (2nd ed., pp. 62-84). Oxford: Blackwell.

GRIFFITHS, S. W. (2003). Learned recognition of conspecifics by fishes. Fish \& Fisheries, 4, 256-268.

HAMiLTON, W. D. (1964). The genetical evolution of social behaviour I-II. Journal of Theoretical Biology, 7, 1-52.

HENRICH, J. (2001). Cultural transmission and the diffusion of innovations: Adoption dynamics indicate that biased cultural transmission is the predominate force in behavioral change and much of sociocultural evolution. American Anthropologist, 103, 992-1013.

HENRICH, J., \& BOYD, R. (1998). The evolution of conformist transmission and the emergence of between-group differences. Evolution \& Human Behavior, 19, 215-242.

HeNRICH, J., \& GIL-White, F. J. (2001). The evolution of prestige: Freely conferred deference as a mechanism for enhancing the benefits of cultural transmission. Evolution \& Human Behavior, 22, 165-196.

HenRich, J., \& MCELREATH, R. (2003). The evolution of cultural evolution. Evolutionary Anthropology, 12, 123-135.

HigGS, P. G. (2000). The memetic transition: A simulation study of the evolution of learning by imitation. Proceedings of the Royal Society of London B, 267, 1355-1361.

Hunt, G. R., \& GraY, R. D. (2003). Diversification and cumulative evolution in New Caledonian crow tool manufacture. Proceedings of the Royal Society of London B, 270, 867-874.

Kelley, J. L., Evans J. P., Ramnarine, I. W., \& Magurran, A. E. (2003). Back to school: Can antipredator behaviour in guppies be enhanced through social learning? Animal Behaviour, 65, 655-662.

KeNDAL, J. R. (2003). An investigation into social learning: Mechanisms, diffusion dynamics, functions and evolutionary consequences. Unpublished doctoral thesis, University of Cambridge.

KirkPatrick, M., \& DugatKin, L. A. (1994). Sexual selection and the evolutionary effects of copying mate choice. Behavioral Ecology \& Sociobiology, 34, 443-449.

Krause, J. (1993). Transmission of fright reaction between different species of fish. Behaviour, 127, 37-48.

KraUSE, J., \& Godin, J.-G. J. (1994). Shoal choice in the banded killifish (Fundulus diaphanus, Teleostei, Cyprinodontidae): Effects of predation risk, fish size, species composition and size of shoals. Ethology, 98, 128-136.

LaChlan, R. F., CROOKS L., \& LALAND, K. N. (1998). Who follows whom? Shoaling preferences and social learning of foraging information in guppies. Animal Behaviour, 56, 181-190.

LaFleur, D. L., Lozano, G. A., \& Sclafani, M. (1997). Female mate choice copying in guppies, Poecilia reticulata: A re-evaluation. Animal Behaviour, 54, 579-586.

LALAND, K. N. (2001). Imitation, social learning and preparedness. In G. Gigerenzer \& R. Selten (Eds.), Bounded rationality: The adaptive toolbox (pp. 233-247). Cambridge, MA: MIT Press.

Laland, K. N., Odling-Smee, F. J., \& Feldman, M. W. (2000). Niche construction, biological evolution and cultural change. Behavioral \& Brain Sciences, 23, 131-146.

LALAND, K. N., \& Williams, K. (1997). Shoaling generates social learning of foraging information in guppies. Animal Behaviour, $\mathbf{5 3}$ 1161-1169.

LALAND, K. N., \& Williams, K. (1998). Social transmission of maladaptive information in the guppy. Behavioral Ecology, 9, 493-499.

LEFE BVRE, L., \& GIRALDEAU,L.-A. (1994). Cultural transmission in pigeons is affected by the number of tutors and bystanders present during demonstrations. Animal Behaviour, 47, 331-337.

LefeBvRe, L., \& PALAmeta, B. (1988). Mechanisms, ecology and population diffusion of socially-learned food-finding behavior in feral pigeons. In T. R. Zentall \& B. G. Galef, Jr. (Eds.), Social learning. Psychological and biological perspectives (pp. 141-164). Hillsdale, NJ: Erlbaum.

LiNDSTRÖM, K., \& RANTA, E. (1993). Social preferences by male guppies, Poecilia reticulata, based on shoal size and sex. Animal Behaviour, 46, 1029-1031.

MASON, J. R. (1988). Direct and observational learning by redwinged blackbirds (Agelaius phoeniceus): The importance of complex visual stimuli. In T. R. Zentall \& B. G. Galef, Jr. (Eds.), Social learning: Psychological and biological perspectives (pp. 99-115). Hillsdale, NJ: Erlbaum.

McGregor, P. K., Peake, T. M., \& Lampe, H. M. (2001). Fighting fish Betta splendens extract relative information from apparent interactions: What happens when what you see isn't what you get. Animal Behaviour, 62, 1059-1065.

MENZEL, E. W., JR. (1973). Leadership and communication in young chimpanzees. In E. W. Menzel, Jr. (Ed.), Precultural primate behavior (pp. 192-225). Basel: Karger.

MENZEL, E. W.[, JR.] (1974). A group of young chimpanzees in a oneacre field. In A. M. Schrier \& F. Stollnitz (Eds.), Behavior of nonhuman primates: Modern research trends (Vol. 5, pp. 83-153). New York: Academic Press.

MiNEKA, S., \& COOK, M. (1988). Social learning and the acquisition of snake fear in monkeys. In T. R. Zentall \& B. G. Galef, Jr. (Eds.), Social learning: Psychological and biologicalperspectives (pp. 51-73). Hillsdale, NJ: Erlbaum.

NASH, J. F. (1951). Non-cooperative games. Annals of Mathematics, $\mathbf{5 4}$, 286-295.

NicOL, C. J., \& POPE, S. J. (1994). Social learning in small flocks of laying hens. Animal Behaviour, 47, 1289-1296.

Nowicki, S., SeArcy, W. A., \& Peters, S. (2002). Quality of song learning affects female response to male bird song. Proceedings of the Royal Society of London B, 269, 1949-1954.

Odling-Smee, F. J., Laland, K. N., \& Feldman, M. W. (2003). Niche construction: The neglected process in evolution (Monographs in Population Biology, No. 37). Princeton, NJ: Princeton University Press.

PAYNE, R. B. (1996). Song traditions in indigo buntings: Origin, improvisation, dispersal and extinction in cultural evolution. In D. E. Kroodsma \& E. H. Miller (Eds.), Ecology and evolution of acoustic communication in birds (pp. 198-220). Ithaca, NY: Cornell University Press.

Pongrácz, P., Miklósi, A., Kubinyi, E., Topál, J., \& Csányi, V. (2003). Interaction between individual experience and social learning in dogs. Animal Behaviour, 65, 595-603.

REAdER, S. M., \& LALAND, K. N. (EDS.) (2003). Animal innovation. Oxford: Oxford University Press.

Rogers, A. R. (1988). Does biology constrain culture? American Anthropologist, 90, 819-831.

SCHLAG, K. H. (1998). Why imitate, and if so, how? A bounded rational approach to multi-armed bandits. Journal of Economic Theory, 78, $130-156$.

Suboski, M. D., \& Temple ton, J. J. (1989). Life skills training for hatchery fish: Social learning and survival. Fisheries Research, 7, 343-352.

SugitA, Y. (1980). Imitative choice behavior in guppies. Japan Psychological Research, 22, 7-12.

Swaney, W., Kendal, J. R., Capon, H., Brown, C., \& Laland, K. N. (2001). Familiarity facilitates social learning of foraging behaviour in the guppy. Animal Behaviour, 62, 591-598.

Templeton, J. J., \& GiRAldeAU,L.-A. (1996). Vicarious sampling: The use of personal and public information by starlings foraging in a simple patchy environment. Behavioral Ecology \& Sociobiology, 38, 105-113.

TOMASELlO, M. (1994). The question of chimpanzee culture. In R. Wrangham, W. McGrew, F. de Waal, \& P. Heltne (Eds.), Chimpanzee cultures (pp. 301-317). Cambridge, MA: Harvard University Press.

TRIVERS, R. L. (1971). The evolution of reciprocal altruism. Quarterly Review of Biology, 46, 35-57.

VALONE, T. J. (1989). Group foraging, public information, and patch estimation. Oikos, 56, 357-363.

White, D. J., \& Galef, B. G., JR. (1999). Mate-choice copying and conspecific cueing in Japanese quail, Coturnix coturnix japonica. Animal Behaviour, 57, 465-473.

White, D. J., \& GALEF, B. G., JR. (2000). "Culture" in quail: Social influences on mate choices in female Coturnix japonica. Animal Behaviour, 59, 975-979.

WILKINSON, G. (1992). Information transfer at evening bat colonies. Animal Behaviour, 44, 501-518. 


\section{NOTES}

1. This conclusion holds irrespective of whether the asocial and social learning involved is reliant on similar or different underlying psychological processes.

2. A copy-when-asocial-learning-is-costly strategy also underlies Boyd and Richerson's (1995) conclusion that social learning can increase the mean fitness of individuals in a population.

3. One potentially important caveat here is that if the entire population is challenged by a novel problem, perhaps because of a change in the environment, social learning may not be adaptive, since at that point there may be no individual that knows how to behave (Henrich \& Boyd, 1998).

4. A Nash equilibrium is a combination of strategies for the players of a game in which each player's strategy is a best response (i.e., one that maximizes expected payoffs) to the other players' strategies (Nash, 1951).

5. Laland \& Williams's (1998) experiment provides evidence of the social transmission of maladaptive information (i.e., "take the long route"), and of a suboptimal behavioral tradition (of taking the long route), but neither the behavior of the fish (when it pays to shoal for protection from predators) nor the general capacity for social learning (which is typically advantageous), should be described as maladaptive. A failure to distinguish between transmitted information, tradition, behavior, and capacity for social learning has resulted in much confusion in discussions of the adaptive value of social learning.

6. Strictly speaking, only the former hypothesis is in accordance with Boyd and Richerson's (1988) assumptions. In principle, these alternatives could be distinguished through careful experimentation.

7. Here, animals may be adopting a copy-the-most-successful-behavior or copy-if-better strategy. In principle, these alternatives could be distinguished through careful experimentation. For example, demonstration of a copy-successful-individuals strategy would be confirmed if demonstrators whose behavior was observed to be successful on one task A, are copied in another task, B, before or without the observers' knowing whether the demonstrators' behavior in B was or was not successful.

8. By this logic, social learning may be more common among animals of the same sex, size, social rank, and so forth. 